\title{
BMJ Open Link between healthy lifestyle and psychological well-being in Lithuanian adults aged 45-72: a cross-sectional study
}

\author{
Laura Sapranaviciute-Zabazlajeva, ${ }^{1}$ Dalia Luksiene, ${ }^{2}$ Dalia Virviciute, ${ }^{2}$ \\ Martin Bobak, ${ }^{3}$ Abdonas Tamosiunas ${ }^{2}$
}

To cite: SapranaviciuteZabazlajeva L, Luksiene D, Virviciute $\mathrm{D}$, et al. Link between healthy lifestyle and psychological well-being in Lithuanian adults aged 4572: a cross-sectional study. BMJ Open 2017;7:e014240. doi:10.1136/bmjopen-2016014240

- Prepublication history for this paper is available online. To view these files please visit the journal online (http://dx.doi.org/10.1136/ bmjopen-2016-014240).

Received 12 September 2016 Revised 22 January 2017 Accepted 2 February 2017

CrossMark

\begin{abstract}
${ }^{1}$ Health Psychology Department, Institute of Cardiology, Academy of Medicine, Lithuanian University of Health Sciences, Kaunas, Lithuania

${ }^{2}$ Institute of Cardiology, Academy of Medicine, Lithuanian University of Health Sciences, Kaunas, Lithuania

${ }^{3}$ Department of Epidemiology and Public Health, University College London, London, UK
\end{abstract}

Correspondence to Dr Laura Sapranaviciute-

Zabazlajeva;

laura.sapranaviciute@|smuni.It

\section{ABSTRACT}

Objective: This study uses a cross-sectional study design to analyse the connection between psychological well-being (PWB) and components of a healthy lifestyle in the Lithuanian population aged 45-72. The purpose of our study is to establish the links between PWB and lifestyle factors such as physical activity, smoking, alcohol consumption and dietary patterns in people above the age of 44 .

Participants: A stratified sample of 10940 urban citizens aged 45-72 years were randomly selected from the National Population Register. The response rate was $65 \%$.

Methods: PWB was evaluated by using a Control Autonomy Self-realization and Pleasure (CASP-12) questionnaire. The standard questionnaire included questions regarding the respondent's sociodemographic, socioeconomic and social status. The lifestyle questionnaire evaluated behavioural factors as smoking status, alcohol consumption, nutrition habits and physical activity. Objective measurements of cardiovascular disease (CVD) risk factors were taken.

Results: Adjusted for sociodemographic, socioeconomic, social and biological CVD risk factors, the probability of higher PWB increased for physically active men and women and male former smokers. Higher PWB was directly associated with consumption of fresh vegetables and fruits. Responders who consumed potatoes, meat, boiled vegetables and eggs less frequently than average were more likely to have higher PWB. A direct association was ascertained between PWB and consumption of chicken and fish, as well as an inverse association between PWB and consumption of sweets in women.

Conclusions: Healthy lifestyle education efforts should focus on increasing physical activity, controlling smoking and improving diversity in healthy food consumption including the consumption of fresh vegetables and fruits, particularly among older adults with lower PWB.

\section{INTRODUCTION}

Results from previous studies suggest that the adoption of a healthy lifestyle might improve

\section{Strengths and limitations of this study}

- Among the Baltic countries, this is the first study to assess the links between psychological wellbeing (PWB) and lifestyle factors at a population level.

- Large sample size consisting of a diversity of self-reported lifestyles and objective biological risk factors.

- Adjusted logistical regression models controlling for various sociodemographic, social and cardiovascular disease risk factors for precise evaluation of the association between lifestyle factors and PWB.

- Cross-sectional study limits findings to associations between factors, yet no conclusions about causation can be made.

- Although the data set analysed is from the period 2006 to 2008, the findings are still relevant as socioeconomic situation and lifestyle habits did not significantly change.

happiness in older people. ${ }^{1}$ Studies also reveal that a healthy lifestyle is positively associated with psychological well-being (PWB) and negatively associated with psychological symptoms. ${ }^{2}$ An Australian longitudinal study concluded that ageing well is associated with such lifestyle factors as restful sleep, increased physical activity, better nutrition, smoking cessation and a range of social activities. ${ }^{3}$ In this way, older adults can maintain their well-being by implementing a healthy lifestyle, even as they confront age-related diseases and other social stressors. ${ }^{4}$

However, although PWB has been linked with lifestyle factors, results have been quite inconsistent. Most studies show that people with high PWB are less likely to smoke $;^{2} 56$ however, there are a limited number of results. ${ }^{7}$ There is also no clear evidence of an association between alcohol consumption and PWB. ${ }^{7}$ Physical exercise has long been 
linked with psychological health. ${ }^{8}$ Exercise not only prevents weight gain and promotes well-being, ${ }^{5}$ it is even believed to impact the association between PWB and mortality from cardiovascular diseases (CVDs). ${ }^{9}$ Most of the studies analysing associations between dietary patterns and well-being explore connections between consumption of fruits, vegetables and well-being. ${ }^{10}{ }^{11}$ Although many studies point to the positive role of fruits and vegetable consumption in increasing PWB, the evidence is still inconclusive. ${ }^{12}$

The purpose of our study is to establish whether there are direct associations between PWB and the following selected lifestyle factors: physical activity, smoking, alcohol consumption and dietary patterns. We hypothesise that higher PWB is associated with physical activity, no smoking status, less frequent alcohol consumption and healthy dietary patterns, such as more frequent consumption of fruits and vegetables and less frequent consumption of sweets.

\section{METHODS}

\section{Study sample}

Our study presents data collected from the survey within the framework of the international project Health, Alcohol and Psychosocial Factors in Eastern Europe (HAPIEE). ${ }^{13}$ The following data are provided from this cross-sectional study. The baseline survey was conducted during the period 2006-2008. A random sample of 10940 urban men and women from Kaunas city (Lithuania) aged 45-72 years, stratified by sex and age, were randomly selected from the National Population Register. The response rate was $65 \%$, meaning 7115 respondents participated in the survey. Some participants refused or were not able to answer all questions in the questionnaire. Thus, data from 86 male and 82 female participants were deleted from the analysis because of incomplete data. A total of 6947 participants were available for statistical analysis after the exclusion of the missing data. The clinical and demographic characteristics of the sample by gender are presented in table 1 .

\section{Measures}

\section{PWB measures}

PWB was evaluated by a Control Autonomy Self-realization and Pleasure (CASP-12) questionnaire. ${ }^{14}$ It is composed of 12 statements. Participants indicate how often (often, sometimes, not often, never) each statement applies to them. The total score ranges from 12 to 48, where a higher score represents higher PWB. Participants were labelled as having a higher PWB if their CASP-12 score was higher or equal to the median: $\geq 40$ in men and $\geq 38$ in women.

\section{Depressive symptoms}

Depressive symptoms were measured using the 10-item Center for Epidemiologic Studies Depression Scale
(CESD-10). ${ }^{15}$ Participants were asked to evaluate the presence of 10 depressive symptoms during the past week on a two-point scale-1 (yes) and 0 (no) - resulting in a total score between 0 and 10 . Based on prior recommendations, participants with CESD-10 scores of 4 or more were classified as having depressive symptoms, and participants with a CESD-10 score lower than 4 as without depressive symptoms. ${ }^{1617}$

\section{Sociodemographic, socioeconomic, social and lifestyle factors}

The standard questionnaire included questions regarding the respondent's sociodemographic factors, such as age, marital status and number of children; and socioeconomic factors, such as education and employment status. Five categories of marital status (married, cohabiting, single, widowed and divorced) and five levels of education (university, college, vocational, primary and secondary) were listed in the questionnaire. Participants were classified as not having children, having one, two or three and more children. Employment status was derived by classifying participants into employed, employed-retired, employed-disabled, disabled, retired and unemployed groups. Study participants were also classified by social activity and social participation. Social activity was evaluated by statements about participating in clubs, going to church, restaurants, theatres, sports clubs, etc. Participants were divided into three groups: low, moderate and high social activity. Social participation shows the percentage of the sample being a member of a social organisation.

The questionnaire also evaluated behavioural factors such as smoking status, alcohol consumption, nutrition habits and physical activity. Smoking habits were assessed by classifying participants into three groups: current smokers, former smokers and never-smokers. Alcohol consumption was measured by asking participants how often they drink alcohol: every day, 2-4 times per week, once per week, 1-3 times per month, less than once per month, never. Physical activity was determined by the mean length of time spent per week during leisure time in winter and summer for walking, moderate and hard work like gardening and other physical activities. The respondents were categorised into two groups according to their physical activity in leisure time: physically active (10 hours or more) and inactive ( $<10$ hours). Nutrition habits were evaluated using a food frequency questionnaire. Food groups included in the food frequency questionnaire were: potatoes, porridges and cereals, cheese, curd cheese, chicken, fish, meat, sausage, eggs, fresh carrots, other fresh vegetables, boiled vegetables, fresh fruit, natural juice, candies, chocolate and cakes. There were six possible responses for each food group: rarely or never; 2-3 times per month; once per week 2-3 times per week; 4-6 times per week; every day. Factor analysis was employed to reduce the number of food items. Data on exploratory factor analysis are presented in our previous paper. ${ }^{18}$ Factor analysis of the main dietary patterns 
Table 1 Baseline characteristics of the study population

\begin{tabular}{|c|c|c|c|}
\hline Variables & Men & Women & p Value \\
\hline Age, years, mean (SD) & $60.6(7.6)$ & $60.4(7.6)$ & 0.987 \\
\hline \multicolumn{4}{|l|}{ Body mass index, $\%(95 \% \mathrm{Cl})$} \\
\hline$<25 \mathrm{~kg} / \mathrm{m}^{2}$ & 22.2 (20.7 to 23.6$)$ & 19.2 (18.0 to 20.4$)$ & \multirow[t]{3}{*}{$<0.001$} \\
\hline $25-29.9 \mathrm{~kg} / \mathrm{m}^{2}$ & 44.0 (42.3 to 45.7$)$ & 35.4 (33.9 to 36.9$)$ & \\
\hline$\geq 30 \mathrm{~kg} / \mathrm{m}^{2}$ & 33.8 (32.2 to 35.5$)$ & 45.4 (43.8 to 47.0$)$ & \\
\hline Arterial hypertension, \% (95\% Cl) & $74.0(72.5$ to 75.5$)$ & 63.6 (62.1 to 65.2$)$ & $<0.001$ \\
\hline \multicolumn{4}{|l|}{ Triglycerides, \% (95\% Cl) } \\
\hline$<1.69 \mathrm{mmol} / \mathrm{L}$ & 72.9 (71.4 to 74.4$)$ & 72.8 (71.4 to 74.2$)$ & \multirow[t]{2}{*}{0.489} \\
\hline$\geq 1.7 \mathrm{mmol} / \mathrm{L}$ & 27.1 (25.6 to 28.6$)$ & 27.2 (25.8 to 28.6$)$ & \\
\hline \multicolumn{4}{|l|}{ HDL cholesterol, \% (95\% Cl) } \\
\hline$<1.29 \mathrm{mmol} / \mathrm{L}$ & $14.4(13.1$ to 15.6$)$ & 24.6 (23.2 to 26.0$)$ & \multirow[t]{2}{*}{$<0.001$} \\
\hline$\geq 1.3 \mathrm{mmol} / \mathrm{L}$ & 85.6 (84.4 to 86.9$)$ & 75.4 (74.0 to 76.8$)$ & \\
\hline \multicolumn{4}{|l|}{ LDL cholesterol, \% (95\% Cl) } \\
\hline$<3.00 \mathrm{mmol} / \mathrm{L}$ & 24.4 (22.8 to 25.9$)$ & 19.7 (18.5 to 21.0$)$ & \multirow[t]{3}{*}{$<0.001$} \\
\hline $3.00-4.09 \mathrm{mmol} / \mathrm{L}$ & 43.1 ( 41.4 to 44.9 ) & 41.6 (40.0 to 43.1$)$ & \\
\hline$\geq 4.10 \mathrm{mmol} / \mathrm{L}$ & 32.5 (30.7 to 34.2$)$ & 38.7 (37.1 to 40.3$)$ & \\
\hline \multicolumn{4}{|l|}{ Glucose, \% (95\% Cl) } \\
\hline$<5.5 \mathrm{mmol} / \mathrm{L}$ & 47.3 (45.6 to 49.0$)$ & $44.0(42.5$ to 45.6$)$ & \multirow[t]{3}{*}{0.019} \\
\hline $5.55-6.98 \mathrm{mmol} / \mathrm{L}$ & 43.3 (41.6 to 45.0$)$ & 46.4 (44.8 to 47.9$)$ & \\
\hline$\geq 6.99 \mathrm{mmol} / \mathrm{L}$ & 9.4 (8.4 to 10.4$)$ & $9.6(8.6$ to 10.5$)$ & \\
\hline \multicolumn{4}{|l|}{ Smoking status, \% (95\% Cl) } \\
\hline Current & 30.6 (29.0 to 32.2$)$ & 9.8 (8.9 to 10.7$)$ & \multirow[t]{3}{*}{$<0.001$} \\
\hline Former & 30.9 (29.3 to 32.5$)$ & 7.1 (6.3 to 7.9$)$ & \\
\hline Never & 38.5 (36.8 to 40.1$)$ & 83.1 (81.9 to 84.3$)$ & \\
\hline \multicolumn{4}{|l|}{ Alcohol consumption, \% (95\% Cl) } \\
\hline Every day & $6.0(5.2$ to 6.8$)$ & $1.0(0.7$ to 1.4$)$ & \multirow[t]{6}{*}{$<0.001$} \\
\hline 2-4 times per week & 16.1 (14.9 to 17.4$)$ & 2.8 (2.3 to 3.3$)$ & \\
\hline Once a week & $16.2(14.9$ to 17.5$)$ & $6.9(6.1$ to 7.71$)$ & \\
\hline 1-3 times per month & 33.9 (32.2 to 35.5$)$ & 30.6 (29.1 to 40.0$)$ & \\
\hline Less than once a month & 22.5 (21.0 to 24.0$)$ & 50.9 (49.3 to 52.4$)$ & \\
\hline Never & $5.3(4.5$ to 6.1$)$ & $7.8(7.0$ to 8.7$)$ & \\
\hline Physically active, \% (95\% Cl) & $68.0(66.4$ to 69.6$)$ & 80.4 (79.1 to 81.6$)$ & $<0.001$ \\
\hline \multicolumn{4}{|l|}{ Nutrition habits, $\%(95 \% \mathrm{Cl})$} \\
\hline Fresh vegetables and fruit consumption & 50.3 (48.6 to 52.1$)$ & $56.8(55.1$ to 58.2$)$ & $<0.001$ \\
\hline Sweets consumption & 48.8 (47.1 to 50.5$)$ & 45.9 (44.3 to 47.5$)$ & 0.009 \\
\hline Porridge, cereals, curd, cheese consumption & 36.8 (35.1 to 38.5$)$ & 62.3 (60.8 to 63.9$)$ & $<0.001$ \\
\hline Potatoes, meat, boiled vegetables and eggs & $62.0(60.3$ to 63.7$)$ & 43.5 (42.0 to 45.1$)$ & $<0.001$ \\
\hline Chicken and fish consumption & $55.2(53.5$ to 57.0$)$ & $50.2(48.6$ to 51.7$)$ & $<0.001$ \\
\hline \multicolumn{4}{|l|}{ Marital status, $\%(95 \% \mathrm{Cl})$} \\
\hline Married & $83.4(82.1$ to 84.7$)$ & 56.2 (54.7 to 57.8$)$ & \multirow[t]{5}{*}{$<0.001$} \\
\hline Single & $1.9(1.4$ to 2.4$)$ & 5.8 (5.0 to 6.4$)$ & \\
\hline Cohabiting & $1.6(1.2$ to 2.1$)$ & $0.8(0.5$ to 1.1$)$ & \\
\hline Divorced & 7.8 (6.8 to 8.7$)$ & $16.0(14.83$ to 17.1$)$ & \\
\hline Widowed & $5.3(4.5$ to 6.1$)$ & $21.2(19.9$ to 22.5$)$ & \\
\hline \multicolumn{4}{|l|}{ Number of children, \% (95\% Cl) } \\
\hline 0 & $6.9(6.0$ to 7.8$)$ & $11.1(10.1$ to 12.1$)$ & $<0.001$ \\
\hline 1 & 24.0 (22.6 to 25.5$)$ & 28.8 (27.4 to 30.2$)$ & \\
\hline 2 & 56.1 (54.3 to 57.8$)$ & 50.5 (49.0 to 52.1$)$ & \\
\hline 3 and more & $13.0(11.9$ to 14.2$)$ & 9.6 (8.6 to 10.5$)$ & \\
\hline Education level, \% (95\% Cl) & & & \\
\hline Primary & 7.2 (6.3 to 8.0$)$ & $7.1(6.25$ to 7.9$)$ & $<0.001$ \\
\hline Vocational & 10.7 (9.6 to 11.7$)$ & 8.4 (7.6 to 9.3$)$ & \\
\hline Secondary & 30.5 (28.7 to 31.8$)$ & 25.3 (23.8 to 26.6$)$ & \\
\hline College & 18.0 (16.6 to 19.2$)$ & 27.2 (25.7 to 28.5$)$ & \\
\hline University & 33.6 (31.8 to 35.0 ) & 32.0 (30.4 to 33.3$)$ & \\
\hline Employment status, \% (95\% Cl) & & & \\
\hline Employed & 40.4 (38.7 to 42.1$)$ & 32.4 (30.9 to 33.9$)$ & $<0.001$ \\
\hline Employed-retired & $19.6(18.2$ to 21.0$)$ & $14.6(13.5$ to 15.7$)$ & \\
\hline
\end{tabular}


Table 1 Continued

\begin{tabular}{|c|c|c|c|}
\hline Variables & Men & Women & p Value \\
\hline Employed-disabled & 4.2 (3.5 to 4.9$)$ & 3.3 (2.8 to 3.9$)$ & \\
\hline Unemployed & 2.7 (2.1 to 3.2$)$ & 3.4 (2.9 to 4.0$)$ & \\
\hline Retired & 22.8 (21.3 to 24.2$)$ & 35.9 (34.3 to 37.8$)$ & \\
\hline Disabled & $10.3(9.2$ to 11.3$)$ & $10.4(9.4$ to 11.3$)$ & \\
\hline Social participation, \% (95\% Cl) & $16.2(14.9$ to 17.4$)$ & $12.9(11.8$ to 14.0$)$ & $<0.001$ \\
\hline \multicolumn{4}{|l|}{ Social activity, \% (95\% Cl) } \\
\hline Low & 34.8 (33.2 to 36.5$)$ & 28.5 (27.1 to 29.9$)$ & $<0.001$ \\
\hline Moderate & 33.7 (32.1 to 35.3$)$ & 39.6 (38.1 to 41.2$)$ & \\
\hline High & 31.5 (29.9 to 33.1$)$ & 31.9 (30.4 to 33.3$)$ & \\
\hline $\mathrm{CHD}, \%(95 \% \mathrm{Cl})$ & $18.3(17.0$ to 19.7$)$ & 20.0 (18.7 to 21.2$)$ & 0.041 \\
\hline Depressive symptoms, \% (95\% Cl) & 15.6 (14.3 to 16.8$)$ & 29.9 (28.4 to 31.3$)$ & $<0.001$ \\
\hline \multicolumn{4}{|l|}{ Higher PWB, \% (95\% Cl) } \\
\hline$\geq$ Median & 52.8 (51.0 to 54.6$)$ & 55.2 (53.6 to 56.9$)$ & 0.026 \\
\hline
\end{tabular}

revealed five-factor nutrition habits: consumption of fresh vegetables and fruit, consumption of sweets, consumption of porridge and cereals, consumption of potatoes, meat, boiled vegetables and eggs, and consumption of chicken and fish. A dichotomousdependent variable was constructed by dividing factor scores into two groups $(1-$ more frequent than average consumption of particular food group, 0 -less frequent than average consumption).

\section{Cardiovascular diseases}

Coronary heart disease (CHD) was determined through the following procedures-first, documented history of myocardial infarction (MI) and (or) ischaemic changes on ECG coded by the Minnesota codes (MC) 1-1 or 1$2 ;{ }^{19}$ second, angina pectoris was defined by the G. Rose questionnaire (without MI and (or) MC 1-1 or 1-2; $3) ;{ }^{20}$ third, ECG findings by MC $1-3,4-1,4-2,4-3,5-1$, $5-2,5-3,6-1,6-2,7-1,8-3$ (without MI and (or) MC 1$1,1-2$ and without angina pectoris). Arterial hypertension was defined as systolic blood pressure $\geq 140 \mathrm{~mm} \mathrm{Hg}$ and/or diastolic blood pressure $\geq 90 \mathrm{~mm} \mathrm{Hg}$, or normal blood pressure $(<140 / 90 \mathrm{~mm} \mathrm{Hg})$ if the person had taken antihypertensive drugs within the past 2 weeks.

\section{Objective measurements}

Blood pressure was measured three times, using an oscillometric device (Omron M5-I) after 5 min rest. The mean of three systolic and diastolic blood pressure tests was used. Waist circumference was measured by a standard meter within accuracy of $0.5 \mathrm{~cm}$. Body mass index (BMI) was calculated as weight (kilograms) divided by the square of height (metres).

Biochemical analyses were performed for participants on an empty stomach. Serum samples from the baseline survey were analysed in one batch in the WHO Regional Lipid Reference Centre, Institute of Clinical and Experimental Medicine, Prague (Czech Republic). Lipid concentrations in the serum were measured by the conventional enzymatic method. The concentration of glucose in capillary blood was determined by using an individual glucometer 'Glucotrend'. ${ }^{21}$

\section{Statistical analysis}

Statistical analyses were performed using the statistical software package SPSS V.19.0 for Windows. Analysis was performed separately for men and women. The prevalence of lifestyle factors was compared in gender groups via $\chi^{2}$ tests. Mean differences were tested via t-test. Proportions were compared using $\mathrm{z}$ tests. The difference was considered to be statistically significant when $\mathrm{p}<0.05$.

For multivariate analysis, we entered all variables that were significantly associated with higher PWB in the univariate logistic regression analysis. Multiple logistic regression analysis using the likelihood ratio criterion was used to analyse risk factors associated with PWB at a significance level of 0.05 . ORs and 95\% CIs were estimated by the multivariate logistic regression for higher PWB. Two models were assessed. Model 1 included age, lifestyle (smoking, alcohol consumption, physical activity, nutrition factors) and biological (BMI, blood lipids, glucose level and arterial hypertension) CVD risk factors. Model 2 included variables of model 1 plus sociodemographic and socioeconomic factors, depressive symptoms, and CHD.

\section{RESULTS}

Table 1 presents the characteristics of the study population. CVD risk factors such as obesity $\left(\mathrm{BMI} \geq 30 \mathrm{~kg} / \mathrm{m}^{2}\right)$, low high-density lipoprotein cholesterol level $(<1.29 \mathrm{mmol} / \mathrm{L})$, high low-density lipoprotein cholesterol level $(\geq 4.10 \mathrm{mmol} / \mathrm{L})$ and increased glucose level $(\geq 5.5 \mathrm{mmol} / \mathrm{L})$ were more prevalent in women in comparison to men $(\mathrm{p}<0.05)$. CHD was also more prevalent in women. However, arterial hypertension and some unhealthy lifestyle habits such as frequent alcohol consumption and regular smoking status were more 
prevalent in men $(\mathrm{p}<0.001)$. Women were more physically active and their nutrition habits were healthier than men. They also had higher PWB compared with men. Moreover, women were better educated and more socially active. Nevertheless, the prevalence of depressive symptoms was significantly higher in women compared with men. Also the proportion of divorced and widowed participants was higher among women. There were more employed men and more retired women in the study population.

Table 2 shows descriptive characteristics of the study participants by PWB groups (lower PWB and higher PWB).

Significant associations were found in the distribution of the four major lifestyle habits across the two categories of PWB. Men in the higher PWB group were more likely to be never-smokers, physically active and to report healthier nutrition habits such as higher intake of fresh vegetables and fruit; porridge, cereals, curd and cheese. However, they tend to consume sweets more often. Men in the higher PWB group consumed alcohol less frequently than the men in the lower PWB group. Women in the higher PWB group were more likely to be physically active and to report healthier nutrition habits such as higher intake of fresh vegetables and fruits, chicken and fish, and lower intake of porridge, cereals, curd and cheese. They were more likely to drink alcohol more frequently.

Multivariable adjusted ORs of higher PWB according to lifestyle habits are presented in table 3. ORs for having higher PWB were higher for male and female former smokers, never-smokers and men who consumed alcohol less frequently. Increased physical activity was associated with higher PWB in both genders (model 1). Logistic regression analysis revealed that dietary habits were differently associated with higher PWB. Model 2 included variables of model 1 plus sociodemographic, socioeconomic and social factors, depressive symptoms, and CHD. The probability of higher PWB increased for former smokers only in men. However, physical activity increased the probability of higher PWB in both genders. Higher PWB was directly associated with consumption of fresh vegetables and fruits in men and women. Conversely, responders who consumed potatoes, meat, boiled vegetables and eggs less frequently than average had a higher probability of higher PWB. Chicken and fish consumption was directly associated with higher PWB in women. Women consuming more sweets tended to have a lower PWB (table 3).

\section{DISCUSSION}

Our study of older Lithuanians established associations between PWB and lifestyle factors such as physical activity, healthy eating, alcohol consumption and smoking. The relationship between smoking habits and PWB varied by the gender of the respondent. Men in the higher PWB group were more likely to be never-smokers as compared with men in the lower PWB group. After adjustment for sociodemographic, socioeconomic and social factors, depressive symptoms and CHD, the probability of higher PWB significantly increased for male former smokers as compared with regular smokers. It is quite likely that the association is significant only among

Table 2 Distribution of the lifestyle factors according to the PWB

\begin{tabular}{|c|c|c|c|c|}
\hline \multirow[b]{2}{*}{ Lifestyle factors } & \multicolumn{2}{|l|}{ Men } & \multicolumn{2}{|l|}{ Women } \\
\hline & $\begin{array}{l}\text { Lower PWB } \\
\text { <Median }\end{array}$ & $\begin{array}{l}\text { Higher PWB } \\
\geq \text { Median }\end{array}$ & $\begin{array}{l}\text { Lower PWB } \\
\text { <Median }\end{array}$ & $\begin{array}{l}\text { Higher PWB } \\
\geq \text { Median }\end{array}$ \\
\hline \multicolumn{5}{|l|}{ Smoking status (\%) } \\
\hline Current & 33.9 & $26.9^{\star \star \star}$ & 10.1 & 9.7 \\
\hline Former & 30.3 & 32.0 & 6.9 & 7.2 \\
\hline Never & 35.8 & $41.1^{\star \star}$ & 83.0 & 83.1 \\
\hline \multicolumn{5}{|l|}{ Alcohol consumption (\%) } \\
\hline Every day & 7.5 & $5.2^{\star \star}$ & 0.8 & 1.2 \\
\hline 2-4 times per week & 14.6 & $17.7^{\star}$ & 2.1 & 3.3 \\
\hline Once a week & 15.7 & 16.6 & 5.8 & $8.1^{\star \star}$ \\
\hline 1-3 times per month & 33.0 & 33.7 & 27.2 & $34.3^{\star \star}$ \\
\hline Less than once a month & 23.3 & 21.8 & 53.8 & $48.0^{\star \star}$ \\
\hline Never & 5.9 & 5.0 & 10.3 & $5.1^{\star \star}$ \\
\hline Physically active (\%) & 64.5 & $72.4^{\star \star \star}$ & 76.5 & $84.2^{\star \star \star}$ \\
\hline \multicolumn{5}{|l|}{ Nutrition habits (\%) } \\
\hline More frequent fresh vegetables, fruit consumption & 44.7 & $57.3^{\star \star \star}$ & 46.8 & $65.3^{\star \star \star}$ \\
\hline More frequent sweets consumption & 46.3 & $51.6^{\star \star}$ & 45.9 & 46.1 \\
\hline More frequent porridge, cereals, curd and cheese consumption & 34.9 & $38.7^{\star}$ & 62.4 & 62.5 \\
\hline $\begin{array}{l}\text { More frequent potatoes, meat, boiled vegetables and eggs } \\
\text { consumption }\end{array}$ & 64.0 & $60.1^{*}$ & 46.7 & $41.3^{\star \star}$ \\
\hline More frequent chicken and fish consumption & 54.2 & 56.8 & 47.3 & $53.0^{\star \star \star}$ \\
\hline
\end{tabular}




\begin{tabular}{|c|c|c|c|c|}
\hline & ORs and $95 \% \mathrm{Cls}$ & & & \\
\hline & Model 1 & & Model 2 & \\
\hline Lifestyle factors & Men & Women & Men & Women \\
\hline \multicolumn{5}{|l|}{ Smoking status } \\
\hline Current & 1 & 1 & 1 & 1 \\
\hline Former & $1.24(1.01 \text { to } 1.53)^{*}$ & $1.09(0.77$ to 1.54$)$ & $1.26(1.01 \text { to } 1.58)^{\star}$ & 1.15 (0.78 to 1.69$)$ \\
\hline Never & $1.29(1.06 \text { to } 1.57)^{\star}$ & $1.33(1.04 \text { to } 1.71)^{\star}$ & $1.14(0.92$ to 1.41$)$ & $1.20(0.91$ to 1.58$)$ \\
\hline \multicolumn{5}{|l|}{ Alcohol consumption } \\
\hline Every day & 1 & 1 & 1 & 1 \\
\hline $2-4$ times per week & $1.67(1.15 \text { to } 2.4)^{\star \star}$ & 1.19 (0.52 to 2.73$)$ & $1.43(0.96$ to 2.12$)$ & $1.08(0.43$ to 2.72$)$ \\
\hline Once a week & $1.44(1.0$ to 2.08$)$ & 1.16 (0.54 to 2.47$)$ & 1.37 (0.92 to 2.04$)$ & $1.0(0.43$ to 2.32$)$ \\
\hline $1-3$ times per month & 1.34 (0.95 to 1.89$)$ & 1.05 (0.52 to 2.16$)$ & $1.28(0.89$ to 1.85$)$ & 0.96 (0.43 to 2.13 ) \\
\hline Less than once a month & $1.23(0.86$ to 1.75$)$ & 0.80 (0.39 to 1.62$)$ & $1.29(0.88$ to 1.90$)$ & 0.92 (0.43 to 2.04$)$ \\
\hline Never & $1.24(0.78$ to 1.95$)$ & $0.51(0.24$ to 1.09$)$ & 1.61 (0.98 to 2.63$)$ & $0.70(0.30$ to 1.61$)$ \\
\hline Physically active & $1.37(1.16 \text { to } 1.61)^{\star \star *}$ & $1.54(1.29 \text { to } 1.85)^{\star \star \star}$ & $1.28(1.07 \text { to } 1.54)^{\star \star}$ & $1.37(1.12 \text { to } 1.69)^{\star *}$ \\
\hline More frequent fresh vegetables and fruit consumption & $1.56(1.33 \text { to } 1.82)^{\star * *}$ & $2.0(1.74 \text { to } 2.31)^{\star \star *}$ & $1.36(1.15 \text { to } 1.61)^{\star \star \star}$ & $1.58(1.34 \text { to } 1.86)^{\star \star \star}$ \\
\hline More frequent sweets consumption & $1.17(1.00 \text { to } 1.37)^{\star}$ & $0.90(0.78$ to 1.03$)$ & $1.06(0.89$ to 1.25$)$ & $0.82(0.70 \text { to } 0.96)^{\star}$ \\
\hline More frequent porridge, cereals, curd, cheese consumption & $1.17(0.99$ to 1.37$)$ & $1.04(0.90$ to 1.21$)$ & $1.17(0.98$ to 1.40$)$ & $0.97(0.82$ to 1.14$)$ \\
\hline More frequent potatoes, meat, boiled vegetables, eggs consumption & $0.83(0.71 \text { to } 0.98)^{\star}$ & $0.80(0.69 \text { to } 0.92)^{\star \star}$ & $0.79(0.66 \text { to } 0.93)^{\star \star}$ & $0.83(0.71 \text { to } 0.97)^{\star}$ \\
\hline Chicken, fish consumption & $1.14(0.97$ to 1.32$)$ & $1.29(1.12 \text { to } 1.48)^{\star \star \star}$ & $1.15(0.98$ to 1.36$)$ & $1.23(1.05 \text { to } 1.43)^{\star \star}$ \\
\hline \multicolumn{5}{|c|}{$\begin{array}{l}\text { Model } 1 \text { included age, lifestyle (smoking, alcohol consumption frequency, physical activity and nutrition habits), and biological (body mass index, triglycerides, HDL cholesterol, LDL cholesterol, } \\
\text { glucose level and arterial hypertension) CVD risk factors. } \\
\text { Model } 2 \text { included variables of model } 1 \text { plus sociodemographic, social and socioeconomic factors (education, marital status, number of children, employment status, and membership of social } \\
\text { organization, social activity), depressive symptoms, CHD. } \\
\text { Bold typeface indicates significance. } \\
{ }^{\circ} p<0.05 ;{ }^{* \star} p<0.01 ; \text {; }{ }^{* \star *} p<0.001 \text {. } \\
\text { HDL, hiah-density lipoprotein: LDL, low-density lipoprotein; CHD, coronary heart disease; PWB, psychological well-being. }\end{array}$} \\
\hline
\end{tabular}

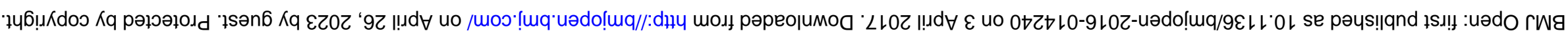


men because the prevalence of regular smoking among middle-aged and elderly women is quite low (lower than $10 \%)$. The study revealed that the association between smoking habits and PWB is quite weak. It may be considered that smoking is more strongly related with mental disorders and negative factors of mental health as compared with positive PWB, which was the subject of our study. Longitudinal epidemiological studies would likely enable the evaluation and demonstration of the prognostic impact of smoking habits on PWB. ${ }^{22-24}$ The crosssectional nature of our analysis enabled the demonstration of only an association between the PWB and smoking habits.

The association between alcohol consumption and PWB also varied by gender. Among men who drank alcohol 2-4 times per week, the odds of higher PWB were significantly higher compared with men drinking alcohol every day. Even after adjustment for other factors, the odds of higher PWB among non-drinkers was higher compared with drinkers. Alcohol consumption was not significantly related with PWB in women after adjustment to other factors.

The relationship between drinking large amounts of alcohol and lower PWB has also been demonstrated by other studies. ${ }^{25}$ However, we did not find any study presenting results about this association disaggregated by the sex of the respondents. It may be suggested that a significant association between alcohol drinking and PWB is more characteristic of men because the prevalence of problematic alcohol use among women is rather low. Previous research also reported a similar association between depressive symptoms and problematic alcohol drinking. ${ }^{26}$ The results of other studies showed that people having a higher level of negative affect are more likely to engage in harmful alcohol use. ${ }^{27}$

Physical activity increased the probability of higher PWB in both genders (data adjusted by sociodemographic, socioeconomic and social factors, depressive symptoms, and CHD). Several previous epidemiological studies in the middle-aged and elderly population also found that physical activity was related to PWB. A study in the UK showed higher levels of PWB among physically active persons as compared with inactive persons. ${ }^{28}$ Meta-analysis of the results of 36 such studies also revealed the relationship between physical activity and PWB in older adults. Social-cognitive theory was used by the authors of the meta-analysis to explain the effect of physical activity on PWB: PWB is represented by selfefficacy and perceived individual ability to meet one's needs. With age, the ability to perform daily activities weakens; therefore, physical activity allows for feelings of self-efficacy and a sense of control over life. ${ }^{29}$ It can be assumed that physical activity also reveals a person's ability to move and better cope with everyday activities, which leads to higher PWB. Unfortunately, the performance of daily activities was not evaluated in our study. However, after adjustment for disability and other health-related variables, a significant association between physical activity and PWB persisted. This indicates an independent association between physical activity and PWB.

Higher PWB was positively associated with the consumption of fresh vegetables and fruits in men and women. Also, it was indicated that respondents who consumed potatoes, meat, boiled vegetables and eggs less frequently than average had a higher probability of higher PWB. Chicken and fish consumption was directly associated with a higher PWB and consumption of sweets was inversely associated with higher PWB in women. Previous studies provide strong evidence of a causal relationship between fruit and vegetable consumption and positive well-being. ${ }^{1}$ Well-being especially increases with consumption of fruits and vegetables on a daily basis. ${ }^{10-12}$ However, scientific evidence of an association between PBW and other nutrition habits (meat, fish or sweets) is not clear enough.

\section{Strengths and limitations}

To the best of our knowledge, this is the first study to assess at a population level the links between PWB and lifestyle in the Baltic countries. The strengths of this study include the large study sample with the availability of multiple lifestyle and biological risk factors. We used adjusted logistic regression models for the evaluation of an association between lifestyle factors and higher PWB. Self-reported variables such as smoking, alcohol consumption, physical activity, nutrition factors, social, socioeconomic and sociodemographic factors were included in the logistic regression, as were objectively measured variables such as BMI, blood lipids, glucose level and blood pressure.

Some limitations of our study need to be addressed. First, due to the cross-sectional nature of the study, it is still not clear whether smoking, low physical activity and some nutrition habits reduce PWB levels or if lower PWB results in the adoption of unhealthy lifestyle habits. Longitudinal studies should be undertaken. Second, selfreported evaluation of lifestyle factors like physical activity and nutrition habits may be an imprecise method for estimating the type and duration of physical activity and dietary habits. More precise measures should be involved in future studies. Moreover, there may be some potential confounding factors that were not analysed in the study, especially as the sample was taken from the complex ecosystem of Lithuania's second largest city. Furthermore, this study represents only one country and results cannot be reasonably generalised further than Lithuania. Although the data set analysed is from the period 2006 to 2008, the findings are still relevant as socioeconomic situation and lifestyle habits did not significantly change from 2008 to $2014 .^{30}$

\section{CONCLUSIONS}

Former smoking status, physical activity and healthy nutrition habits increased the probability of higher 
PWB. Healthy lifestyle education efforts should focus on increasing physical activity, controlling smoking, and improving healthy and diverse food consumption, particularly among older adults with lower PWB.

Contributors LS-Z, DL and AT contributed to the concept and design of the manuscript, data interpretation and writing. DV contributed to the data analysis and interpretation. LS-Z, AT and MB contributed to the final approval of the manuscript.

Funding Research Council of Lithuania, grant number SEN-02/2015. Wellcome Trust, 081081/Z/06/Z. US National Institute on Aging, 1ROI AG23522.

Competing interests None declared

Patient consent Obtained.

Ethics approval Regional Biomedical Research Ethics Committee at the Lithuanian University of Health Sciences and by the UCLH Research Ethics Committee Alpha at University College London, UK.

Provenance and peer review Not commissioned; externally peer reviewed.

Data sharing statement No additional data are available.

Open Access This is an Open Access article distributed in accordance with the Creative Commons Attribution Non Commercial (CC BY-NC 4.0) license, which permits others to distribute, remix, adapt, build upon this work noncommercially, and license their derivative works on different terms, provided the original work is properly cited and the use is non-commercial. See: http:// creativecommons.org/licenses/by-nc/4.0/

\section{REFERENCES}

1. Mujcic R, Oswald A. Evolution of well-being and happiness after increases in consumption of fruit and vegetables. Am J Public Health 2016;106:1504-10.

2. Pahl K, Brook JS, Koppel J, et al. Unexpected benefits: pathways from smoking restrictions in the home to psychological well-being and distress among urban black and Puerto Rican Americans. Nicotine Tob Res 2011:13:706-13.

3. Kendig $\mathrm{H}$, Browing $\mathrm{CJ}$, Thomas SA, et al. Health, lifestyle, and gender influences on aging well: an Australian longitudinal analysis to guide health promotion. Front Public Health 2014;2:1-9.

4. Kahana E, Kelley-Moore J, Kahana B. Proactive aging: a longitudinal study of stress, resources, agency, and well-being in late life. Aging Ment Health 2012;16:438-51.

5. Sagara T, Hitomi Y, Kambayashi $Y$, et al. Common risk factors for changes in body weight and psychological well-being in Japanese Male middle-aged workers. Environ Health Prev Med 2009;14:319-27.

6. Barros VV, Kozasa EH, Formagini TD, et al. Smokers show lower levels of psychological well-being and mindfulness than non-smokers. PLOS ONE 2015;10:e0135377.

7. Boehm JK, Kubzansky LD. The heart's content: the association between positive psychological well-being and cardiovascular health Psychol Bull 2012;138:655-91.

8. Scully D, Kremer J, Meade MM, et al. Physical exercise and psychological well-being: a critical review. $\mathrm{Br} J$ Sports Med 1998;32:111-20.

9. Hoogwest MT, Versteeg $\mathrm{H}$, Hansen TB, et al. Exercise mediates the association between positive affect and 5-year mortality in patients with ischemic heart disease. Circ Cardiovasc Qual Outcomes 2013;6:559-66.
10. Blanchflower DG, Oswald AJ, Stewart-Brown SL. Is psychological well-being linked to the consumption of fruit and vegetables? Working Paper. Coventry: Economics Department, University of Warwick. (Warwick economics research paper series (TWERPS), 2012; No.996.

11. Conner TS, Brookie KL, Richardson AC, et al. On carrots and curiosity: eating fruit and vegetables is associated with greater flourishing in daily life. Br J Health Psychol 2015;20:413-27.

12. Rooney C, McKinley MC, Woodside JV. The potential role of fruit and vegetables in aspects of psychological well-being: a review of the literature and future directions. Proc Nutr Soc 2013;72:420-32.

13. Peasey A, Bobak M, Kubinova R, et al. Determinants of cardiovascular disease and other non-communicable diseases in Central and Eastern Europe: rationale and design of the HAPIEE study. BMC Public Health 2006;6:255

14. Hyde M, Wiggins RD, Blane $D$, et al. A measure of quality of life in early old age: the theory, development and properties of a needs satisfaction model (CASP-19). Aging Ment Health 2003;7:186-94.

15. Carpenter JS, Andrykowski MA, Hall L, et al. Psychometrics for two short forms of the center for epidemiologic studies: depression scale. Iss Mentl Health Nurs 1998;19:481-94.

16. Sapranaviciute-Zabazlajeva L, Reklaitiene R, Tamosiunas A, et al. Correlates of depressive symptoms in urban middle-aged and elderly Lithuanians. Soc Psychiatry Psychiatr Epidemiol 2014;49:1199-207.

17. Irwin M, Artin KH, Oxman MN. Screening for depression in the older adult. Criterion validity of the ten-item center for epidemiological studies depression scale. Arch Intern Med 1999;159:1701-4.

18. Luksiene DI, Baceviciene M, Tamosiunas A, et al. Health, alcohol and psychosocial factors in Eastern Europe study: dietary patterns and their association with socio-demographic factors in the Lithuanian urban population of Kaunas city. Int J Public Health 2011:56:209-16.

19. Prineas RJ, Crow RS, Blackburn H. The Minnesota code. Manual of electrocardiographic findings. London: John Wright, 1982.

20. Rose GA, Blackburn H, Gillum RF, et al. Cardiovascular survey methods. Geneva: Cardiovascular Disease Unit, WHO, 1982.

21. Norkus A, Ostrauskas R, Sulcaite R, et al. Classification and diagnosis of diabetes mellitus (methodology recommendations). Lith Endocrinol 2000;3:234-41.

22. Yaffe $\mathrm{K}$, Fiocco AJ, Lindquist $\mathrm{K}$, et al. Predictors of maintaining cognitive function in older adults: the Health ABC study. Neurology 2009;72:2029-35

23. Chodzko-Zajko W. National blueprint: increasing physical activity among adults 50 and older: implications for future physical activity and cognitive functioning research. In: Poon LW, Chodzko-Zajko W, Tomporowski PD, eds. Active living, cognitive functioning and aging. Champaign: Human Kinetics, 2006:1-14.

24. Nooyens AC, van Gelder BM, Verschuren WM. Smoking and cognitive decline among middle-aged men and women: the Deotinchem Cohort Study. Am J Public Health 2008;98:2244-50.

25. Stranges S, Samaraweera PC, Taggart F, et al. Major health-related behaviors and mental well-being in the general population: the Health Survey for England. BMJ Open 2014;4:e005878.

26. Watts $M$. Understanding the coexistence of alcohol misuse and depression. Br J Nurs 2008;17:696-9.

27. Gorka SM, Ali B, Daughters SB. The role of distress tolerance in the relationship between depressive symptoms and problematic alcohol use. Psychol Addict Behav 2012;26:621-6.

28. Steptoe A, Demakakos P, Oliveira C, et al. Distinctive biological correlates of positive psychological well-being in older men and women. Psychosom Med 2012;74:501-8.

29. Netz Y, Wu MJ, Becker BJ, et al. Physical activity and psychological well-being in advanced age: a meta-analysis of intervention studies. Psychol Aging 2005;20:272-84.

30. Grabauskas V, Klumbiene J, Petkeviciene J, et al. Health behaviour among Lithuanian adult population, 2014. Kaunas: Lithuanian University of Health Sciences Press, 2015. 